\title{
XLIV. Memoir upon the compound and smooth or simple eyes of insects, and on the manner in which these two species of eyes concur in vision
}

\section{Marcel de Serres}

To cite this article: M. Marcel de Serres (1814) XLIV. Memoir upon the compound and smooth or simple eyes of insects, and on the manner in which these two species of eyes concur in vision, Philosophical Magazine Series 1, 44:198, 274-292, DOI: $10.1080 / 14786441408637453$

To link to this article: http://dx.doi.org/10.1080/14786441408637453

曲 Published online: 27 Jul 2009.

Submit your article to this journal $[\pi$

Џll Article views: 3

Q View related articles $\sqsubset$ 
proximity to the earth, or ky some other means; and let this cloud, containing themogen, be carried by the wind under another cloud $(B)$ in its natural state, then this clond will become electrified by induction; for the thermogen which it contains will be expelled from it into the air above; and when the cloud $A$ is carried away by the wind, the cloud $B$ will remain electrified, and in a siate contray to that of $A$, like the brass ball in the second experiment.

The air above the cloud $B$ having received an additional charge of thermogen, and this element having a strong attraction for moisture ${ }^{*}$, will attract moisture from the surrounding air, and thus a new cloud will be formed.

When the cloud $\mathrm{A}$ is carried away from under the cloud $\mathrm{B}$, let it be supposed that it passes over or under a very thin cloud, then will this cloud be electrified by induction; but it will receive the same element as that of the cloud $\mathrm{A}$ : the reason of which is shown by the second experiment.

As an excited barometer tube will produce an electrical effect at the distance of four or five feet, it may be supposed that a cloud highly electrified may affect other clouds at the distance of some miles. And hence we may infer that all those various changes, which are daily taking place among the clouds, may arise from that unering law of nature called inducted electricity $\uparrow$.

Lynn, Oct. 10, 1314.

Ez. Walker.

[To be continued.]

XLIV. Memoir upon the compound and smooth or simple Eyes of Insects, and nn the Manner in which these two Species of Eyes concur in Fision. By M. Marcel de Serres, Professor of the Soiences in the Imperial University.

[Continued from page 191.]

\section{On the Mechanism of Vision.}

$\mathrm{T}$

$C_{\text {H }}$ eyes of insects, according to the foregoing observations, are formed in a very differeat manner from those of the vertebral animals, or even the mollusce, among which there also exist distinct lumours Nothing similar is seen in the eyes of insects which, deprived of every hunour, appear as it were to feel the light alnost immediately. Although formed in a manner so pecular, these organs are nevertheless eyes, as we may be

* Phil Migr vol xliii. p. 252.

$+b_{1}$. Irinklin discovered that the clonds would change from positive to negative clectricity, several times in the course of one thunder-gust. 
convineed by squeezing them, or rather by rubbing off from them a blacis stratum which might intercept the action of the rays of light. The insects subjected to this test act completely as if blind, and can no longer direst their efforts rightly for any of the purposes of their existence. These experiments have Jeen so ofen repeated, and are so easily performed, that there is now no naturalist who donbts that the parts called eyes, in insects, really serve all the purposes of vision. But how can these eyes eoncur to vision, and give the insect the faculty of distinguishing objects clearly? These organs, we have said, are constructed in such a way as to fit them to receive the images from objects, by the simple shock of the rays which these objects rellect; and from this way of feeling there must result an extremely lively impression. Insects not having, like vertebral animals, a rontractible pupil, it seems that, as a consequence of this organization, vision ought to be very perfect anong them, on account of the great number of rays which fall continually on the facets of their eyes. Thus these animals seem to distinguish objects at very considerable distances; but the images are painted or stop on their choroid, or they pass beyond, which is very difficult to ascertain, although the first opinion seems most probable.

One of the most learned naturalists of Geneva, M. Prevost, has recently hazarded an opinion very different from that which we here propose, for he thinks that insects are completely myopes. He remarks in the first place, that if we prepare two lenses of the same form and sulystance, their local distances will be in proportion to their diameters, and in general that all the images of points similar!y situated will be also similarly situated. This principle being granter, and true in itself, M. Prevost applies it to insects; but in our opinion the consequences he draws from it are not well founded. "If the eyes of insects," he observes, st were of the sane materials as ours are, and of forms precisely similar, these animals would be singularly myopes; for, in order that the image of any object nay be painted exactly on their retiyzan the distance from the object to the eye would also rcquire to be equally small with respect to the distance required for the luman eye, as is the diameter of their eye with respect to the diameter of ours." That this reasoning may be applicable to insects, there must be a perfect similitude between the matter and the form of their eyes and ours; but we know that there is not the slightest relation between these organs. In fact, the description which we have given of the two species of the eyes of insects, proves that these eyes do not present, as admitted by M. Prevost, different transparent humours, nor liga- 
ments destined to nove them. As to the applications in wibic M. Prevost indulges, and which make him conclude that insects ought to have a distinct view within very narrow limits, they cannot be just, since they west upon facts which are not exact. Thus the same naturalist says, that the eyes resembling in shape those of bees camnot distinguish objects further off than five centimetres and one milimetre; and firially, those of the ant species further tban tive millimetres and one-tenth millieme of a metre*. But it is evident from what has been said, that it is impossible to bring any proof in favour of this asscrtion. Besides, in a problem of this kind, we must pay attention not only to the absolutely diminutive size of the eyes, but also to their relative diameter, as well as to the greater or less convexity; for an eye the diameter of which would be greater than that of another might nevertheless take in less distinctly objects at a certain distance, if at the same time its convexity were more considerable. This is also what observation teaches us in a direct manner, by proving to us that nature has always combined in the kinds of insects which have the most extensive eye-sight, the sphericity of the cornea with the size of the eye. The libellulce, the mantes, the cicindele, as well as most of the lepidopterce, the hymenopterce, and the dipterce, furnish striking examples; and if the size of their eyes is favourable to make them perceive objects at a greater distance, the sphericity of their cornea is not less advantageous for rendering distinct the impression of external objects, by uniting: a greater number of rays, and hindering them from removing from the axis of vision. There is no person, in short, who, in observing the motions of insects, has not remarked, when you wish to catch them, how acutely they see you even at a considerable distance : there are even whole species which cannot be canght until you keep out of their line of vision. It cannot be sad, however, that the insects are then guided by their sense of smelling, for this sense serves them probably only for better getting at their prey when they are still far fron it.

We differ with M. Prevost also when he says that, in order that rision should be useful to insects, they must only see that clearly which passes close to them, probably even at the distance of their feelers and their mouths, a distance at which the human eye sees with such indistinctness, that it may well be said it soes not see at all. In the first place, there is no similitude whatever between the human eye and that of insects, and con-

* Those who have studied the habits of insects must have remarked, that there are certain lepidopterce, some dipter'a, and even orthoptora and lymenojicta, who fly when we approach within the distance of alout six metres.

sequently 
sequently we are not warranted in establishing between these two organs any comparison. All that we can infer is, that it is as necessary for insects to see external objects, as it is for animals of a higher order. The carnivorons insect ought to have the faculty of perceiving its food at a certain distanee, as well as the bird of prey, which suspended in the air would, perhaps, be condemned to die of hunger, if the acuteness of its vision did not ensure its existence.

It must however be observed, that if we only tock into the account the great convexity of the cornea of the eyes of insects, we might well regard these animals as myopes; for we know that the more convex the crystalline is in the eyes of the vertebral animals, the more the syecies which present this arrangement are myopes, particularly if the corncia is very salient, if the humours are very dense, and finally, if the eye is too much sunk. The myopism then depends on the rays being united before reaching the retina: this inconvenience may therefore be remedied by the help of concave glasses, which retard the union of the luminous rays. But the insects which present a very prominent and convex cornea, are they also myopes as a consequence of this arrangement, as would be the case with animals in which the images fall upon the retina, aftcr having traversed humours of different density? Although it is very difficult to solve so intricate a question, it would nevertheless appear that the convexity and protuberance of the cornea ought not to render the insects myopes, since the luminous rays have not to unite rather at one point than at another in order that the effects of vision may be obtained, the latter being effected not because an image is painted on the retina, but by the direct impression of the luminous rays on the optic nerves. The convexity of the cornea being favourable to the collection of the rays, and hindering their dispersion, this form was perhaps the most convenient in the structure of the eyes of insects. It was at least the best adapted for giving them keen sensations, since it tends to make the rays of light fall more perpendicularly. This form is also the most common in this order of animals; and even a considerable number of insects which perceive objects very far off, present their cornea very convex and prominent, such as the papillons and the cicindelce. It muy also be observed, that the concavity of the cornea, by allowing only a small number of rays to enter the eye, ought on that very account to procure less lively and feebler sensations. Thus, we only observe this arrangement in a small number of insects, and merely in the tolerably smooth eyes; but in these species, the compound eyes and the lateral simple eyes may supply the want of the concare eye. 
If the mechanism of vision, such as it is in insects, seemed even to the most eminent anatomists of the present age so difficult to comprehend, it would seem that the way in which they proceeded to the dissection of the compound eyes (for few interfered with the smooth eyes) has been in a great measure the cause. The case would have been different, if, in their dissections of compound eyes, they had not always proceeded from the inside to the outside, a method of operating which may lead into error; for, however little we disturb the optic nerve, the filaments which it gives off, drawn a little back by being disturbed, are no longer exhibited on the tunic of the cornea. If, on the contrary, we carefully remove the cornea, we see in an evident manner the numerous nervous filaments which pass through the tunic. of this membrane, ard spread a little in order to form the peculiar retina of each facet. From that instant, we need no longer explain how the light is able to act on the retina through an opaque varnish.

If we set out from the organization of the eyes of insects, it would appear that we might conceive that vision is produced among them in the following manner:

When the light meets a diaphanons body terminated by a curved surface, which gives it access into its interior, it undergocs a refraction. If its rays being parallel meet the surface of this body, and its medium be denser than that in which the incident rays move, the broken rays will approach the perpendicular by converging upon each other. But if the rays of light fall obliquely, making a very wide angle, the more obliquely will they fall, and the less will they approach the perpendicular. 'These are precisely the differcnt effects which light undergoes in falliag on the cornea, which unites with transpnency a convex surface, and a deuser mediun than that in which the luminous rays move.

In fact, the luminous rays, clirect or reflected, which issue from a visible body, and reach the eye, form different cones, the point of which are at the object, and the bases on the cornea. Those which fall on this membrane in an oblique direction, and by forming a very wide angle, are reffected, and do not traverse. Those, on the contrary, which fall under a convenient angle (an angle which in the human eye is estinated at $48^{\circ}$ ); pass through the cornea, or the facets which compose it, and undergo from it a refraction, which ought to bring them near the perpendicular. It results that these nervous filaments, situated immediately under, are struck by the great qnantity of rays which reach them ${ }_{2}$. and which, as a consequence of their direction, are concentred at the most sensible part of the optic nerve, if we may so express 
it, or at the expansion of this nerve, so that these fitaments may afterwards transmit to the brain the impression of the rays of light, or the image.

The great uumber of facets which compose the cornea, is no obstacle to what we have said; but each of these facets ought to be considered as a cornea, which exercises its action on the rays of light, and makes them undergo the changes necessary for the brain to receive their impression. Nor ought their number to make us suppose that insects oughlt to see objects very much multiplied; for, whatever nay be the number of the nervous filaments which correspond to cach facet, they all set out from the spreading of the optic nerve, which we have considered as a retha sufficiently analogous to that of the red-blooded animals: it is on this retina that are painted the images perceived by the filaments; perhaps even this retina is only destined to tranismit to the brain the impression produced by the rays of light on the optic nerves. This is the more prubable, becanse images can hardly be supposed to exhibit themselves from belind an opaque membrane. The great use of the retina would therefore be to centralize the impression, and to render it unique, if we may so express ourselves.

From what we have seen, if the force and number of the rays of light had been very considerable, these rays might by their too great excitability injure the organ of sight. But nature, equally admirable in her minutest details as in ber most beantiful works, has guarded agriust this inconvenienee; and the varnish of the choroid, as weil as the choroid itself, are the organs which hinder the multiplicity of the lumincus rays from deranging or altering the sensibility of the nerrous filaments. The varnish of the choroid and the membrane of the choroid appear, therefore, destined to absorb the excess of the luminous rays, and to diminish the too great excitability which a very strong light would necessarily hate produced on the optie nerves, according to the conformation of the eyes of insects. The black and opaque bands which we observe in certain species, like the more or less coloured spots in others, seem chicfy intended to absorb the excess of the luminous rays, while those less thick and more transparent facilitate, on the cortrary, the pas age of the light.

It is easy to perceive how necessary this arrangement was to insects : in fact, the latter not having, like mo.t of the vertebral animals, puipils with the property of contracting and dilating, and which, as a consequence of this arrangement, permit these animals to receive only the ravs the most approximating the perpendicular, or the axis of vision, had occasion for an opaque inembrane to absorb the useless rays, or such as might even be 
hurtful to vision. Thus it is particularly by the privation of this membrane, that we may judge of its influence on the sense of sight; and observation proves that it is wanting in all the lucifugce.

According to this way of considering the varnish of the choroid and the choroid itself, we see that the opacity of the latter, always very great, may be no obstacle to vision. It is even possible that this membrane should serve to render it more complete, by preventing the sensibility of the optic nerves from being affected by the almost immediate action of the light on their texture.

As to the air trachere, their chief use seems to be to sustain the spreading of the optic nerve, and to circumscribe it within limits essential to the mechanism of vision. Besides, it is more than probable that the choroid is formed by a heap of tracheæ furnished by the large trachea which surrounds it. These tracheæ, which are distributed over the cellular texture of the choroid, adhere by its upper surface to the varnish, and by its inferior to the spreading of the optic nerve. This organization seems even to be proved by the examination of these various parts. The large circular trachea, placed almost on the same plane with the choroid, furnishes in its texture a very great number of small tracheæ which lose themselves in it, since we can find no trace of them after this membrane. Finally, by a prolonged maceration, we may assure ourselves that the choroid is formed by a close texture, of which, perhaps, the great number of tracheæ which lose themselves in it, is the cause. We might also remark that, in insects, the tracheæ, in being distributed over the cellular texture, form by their union with this texture various membranes, and even several of a considerable extent. The cellular tunic alone of the intestinal tube is a proof of this: it is singular enough that the choroid, formed in the red-blooded animals by a triple vascular texture, is, of all the parts of insects, that which receives most trachex. In short, the choroid is not the only membrane of insects in which we might find a similar resemblance. As the air is the only fluid which has any circulation in them, all the parts which ought to have either a great sensibility, or a great contractibility, generally present a great number of tracheæ. Thus we may always estimate à priori, either the force of a muscle, or the sensibility of an organ, by the tracheæ which we see them receive.

The situation of the optic nerve, with respect to the eye, seems of no consequence to insects. In fact, the numerous nervous filaments corresponding to the facets of the cornea, render it indifferent that the rays of light should fall with more or less exactitude on the insertion of the optic nerve, since the latter can 
only receive the impression from it by the nervous filaments furnished by its spreading.

From what has been said, it is evident that the eve in insects does not present so complex a strueture as the same organ in animals of a superior order. In the eyes of insects we do not observe different humours which by their density can change the direction of the rays of light, by operating a refraction, always in proportion to the nature of the mediums which they pass through. Nevertheless, if the structure of the eye is very simple in this order of animals, it scems to accommodate itself very well with the properties and laws of light, as well as with the oljject which this organ ought to attain. In fact, the cornea, by its transparency, its convexity, and it: more considerable density than that of the air, gives in the first place, on account of its transparency, a passage to the rays of light, while, as a consequence of these two other properties, the rays undergo a refraction, which tends to render convergent the broken fasciculi, and to approximats them to the perpendicular. As the rays which traverse the cornea strike at the same time the nervous filaments, or the retina of the facets of the eye and the tunic of the cornea, they may be perceived by the nerves, and the latter may transmit the impression which they experience to the expansion of the optic nerve. It would, it scems, be in this point that all the rays should be concentrated, in order to form the image; but as, in order to do thic, they woukd have to pass through an opaque membrene, it is difficult to admit it. We must, therefore, suppose that the sensation is there concertred; and probably this species of retina has no other use than that of centralizing and bringing to one point ail the impressicus perceived by the optic filaments.

The protuberance of the cornea seems to be frequently in insects in the ratio of the smallness of their eyes: and this ratio is any thing but indifferent. In short, the more protuberant the cornea, the more numerons are the incident rays; consequently, the rays which reach the nervous flament being in greater number, vision is produecd with a force similar to that which a greater dimension in the eyes could excite; with this difference, however, that insects in this case do not see so far. We may cite as a proof the locnsta lilifolia and acuminata of Fabricius.

Lastly, is remains to make known the singular arrangenent observed in the compomd eves of the litellula vnlgaris, and of the locusta lilifolia, as well us to say a iew words on the structure of the eys of the icuifugce species. The compound eyes of the livellula vulgaris and of the locusta lilifolia present a singular arrangement on account of the tenic of their cornea, which is red in the upper and posterior parts, and of a dear grean in the inferior and anteriof parts, These nwo colours 
are so decided, that the eve appears externally as if formed by two distinct parts Shcild this effect take place on account of the great convexity of the cornea, and even of the position of the eye of this species? For this position and this convexity render the approach of the rays of light easier in the upper part than in the lower, because in this part the eye is perpendicular with respect to the rays, whereas the lower is on the contrary very oblique with respect to them. We also observe that the upper part presents a red colour-a colour which has less refrangibility than the green of the lower part, and which also gives less light. The lower part, to which the approach of the rays of light was very difficult, also presents a green colour, which has more refrangibility than red, and which also gives a greater intensity of light, since, according to the elegant experiments of Herschel, green rays are almost as brilliant as yellow. Thus, the red, sending back rays less brilliant than the green, and being in the point of the eye where the rays of light arrive most easily, would have been placed in this part to absorb, by its greater opacity, the excess of these very rays, which must have injured by their too great cxcitability the optic nerves. The green, on the contrary, presenting moie refraagibility, and a greater intensity of light, would angment the exeitability of the optic nerves in the lower part, and in this way correct the difficulty which the rays might experience in reaching this part of the eye. It is poscible that what we have now said may be well founded : however this may be, we can only regard the explanation of this fact as probabie.

This arrangement is also visible in the lncusta gigantea, in which the eye presents externally all its upper hal of a reddish brown, and its lower half of a very lively green. The centre of the eye, $i$. e. the intermediate pait between those two shades, is of a bright red. These various sharles are owing to the diversity of colour in the tunic of the cornea. We may even remark, that in proportion as the green tint approaches the lower part of the eye, it takes a clearer shade, and verges more and more towards the white. As to the smooth eyes, this species has only two very small conrex mes of a slight red, and situated on the crown of the heat between the compound eycs, and above and in front of the antemx.

There are some coleopterce, like the llaps, the pedinus, and certain tenebriones, which are completely lucifuge, and which, like the blatla, cannot support daylight. Thus, on exposing the species of these differeit genera to a strong light, they are seen to shun it by lowering their heads. Insects being deprived of the pupil, the explanation which has been given of this phænomenon in the accturnal animals cannot be applicable to them. 
Thus, as we have already observed that this genus presented neither choroid nor circular trachen, might we not presume that the excess of the ravs of light which arrive on the optic nerves, not being absorbed by an opacue membrane like the choroid, may injure vision considerably, by increasing too forcibly the excitability of the optic nerves? These insects are as it were rendered stupid by the excess of light: for a contrary reason, a less brisk light not increasing their excitability too much, ought it not to be more favourable for enabling them to perceive objects in a distinct manner? We mipht also add, that the nerrous filaments which attach below the ficets of the cornea, are here very short, so that they are nearer the optic expansion to which sensation is transmitted: having less intermediate between them and the general retina, this impression may be greater. Their sensibility being besides acuter, they require less light to paint in a clear manner the images on the retina, images which are soun afterwards perceived by the brain, on account of the proximity of this organ to the expansion of the optic nerve. We must also remark, that it is in the eyes of the lucifugce alone that the image can be produced, since the impression made by the rays of light on the optic fiaments has not an opaque membrane to pass through to be transmitted to the brain.

As to the black point which is most frequenty observed at the exterior of the compound eyes, a point whiclit seems noveable, and situated in the interior of the eye, so that it should have some relation with the ball of the eye, it seems to be produced by the point of the choroid corresponding to the small circle which gives a passage to the optic nerve, since in this part, the furthest removed from the eye, the deeper violet-coloured tunic onght to produce this point nearly of the breadth of the circle. It is clear that this point is in proportion to the size of the circular apertire through which the optic nerve passes. We see it larger in all the species in which this aperture is formed by the adductor ruscle of the mandibule, as in the locust $a$ and libellula. It is, on the contrary, less considerable in those which have formed it by a circular trachea, like the ary?lus, the truxalis, and the greater number of the diplerce, in which this aperture is still smaller. The species which have their tunic entirely black, like most of the coleopterce and the leymenopierce, as well as the acheta, $8 \mathrm{c}$, do not appear to have any; for it cannot be seen, on account of the colour of the twic. It is, on the contrary, more visible in the species in which this tunic is of a clear colour. In short, the optic nerve does not oppose this arrangement; for the choroid eovers all the internal parts of the eye, exeept in the points where it is traversed by the nervous flaments. As to the movement which we observe in it, it is easy to convince ourselves 
ourselves that it is not a real movement. It seems only to take place, because the point being always fixed, and in the middle of the eye, consequently answering to all the facets of the cornea, on whatever side we observe each facet, the latter being capable of making it what it is, there results that kind of movement which seems to be in the black point or the eye-ball, but which depeids on that made by the observer.

The size of the compound eyes is worthy of being noticed. This size is varjable when we compare it with that of the body, but it seems always more considerable in this respect than in the vertebral animals. We observe in fact, in insects, that the greatest dimension of the compound eyes, in comparison with the body, is as 4 to $\mathrm{I}$, the medium as 10 to $\mathrm{I}$, and the smallest 60 to 1 . I have found the latter proportion in two genera only, and $I$ consider it therefore as extremely rare.

To conclude: the dimensions of which I have spoken, prove how large the eyes of insects are in proportion to their bodies. If it is with difficulty that we can conceive how vision can be effected in these insects, by means of their compound eyes, we shall experience much more difficulty when we contemplate the smooth eyes. These eyes are still more simple than the latter; they are even so simple, that we might fairly doubt if they performed the function of eyes at all, if experience did not dernonstrate it in an evident manner. The greater number of the smooth eyes present a convex form, which is generally observed in the cornea of the compound eyes also: sometimes, however, the cornea of the smooth eyes, instead of presenting this structure, is more or less concave. This last form may nevertheless present some inconveniences in the sense of sight; for, if the light, in passing from a rarer into a denser medium, meets a concave surface, its rays, however parallel they were, become divergent ; a disposition not very favourable to a distinct vision. In fact, so far from the rays diverging too much, it would seem that the optic nerve placed towards the centre of the cornea can scarcely receive the impression of them. As to the plain surface which some smooth eyes exhibit, although it is less favourable to a greater affuence of the rays of light,-it is not an obstacle to vision, since the light passing from a rarer medium into a body, which presents a plano-transparent surface, and a denser medium, its rays will approach the perpendicular at their point of immersion. We may also observe that, the smaller the smooth eyes are, the less plain are their surfaces: thus the mantes, for instance, which have very small eyes, have them projecting in a remarkable manner. The size of the smooth eyes is, besides, very variable in the genera which are most known: thus, it is starely possible to become acquainted with the connexion which 
exists between the projection of the smootin eyes and their smallness.

The light arriving therefore on the extcrnal membrane of the smooth eyes, or upon their coned, undergoes various changes which are connected with the form of the conea. If it be convex, as most generally observed, and the direction of the rays be oblique, by making a very wide angle, they are retlected, and do not traverse it. If the light, on the contrary, falls on the cornea at a convenient angle, its rays pass through that membrane, and undergo from it a refraction which brings them near to the perpenrlicular. Finally; when the cornea is plain, the rays of light will continue their route, by approaching the perpendicular at the point of immersion; whereas, if it were concave, supposing even that the luminous rays were parallel, they would become divergent, and would remove from the axis of vision.

The light which has passed through the cornea, arrives immediately on the kind of retina formed by the optic nerve, a contiunation of the small optic nerves. This retina, shaken by the approach of the rays of light, can transmit the impression of them to the brain. But the few rays which reach the smooth eyes, either on account of the sometimes unfavourable disposition of the cornea, or on account of their smallness, would have been still diminished, if there had been under the nerves a blackness and opaque coating as observed in the compond eres. Thus, in the smooth eyes this coating is most generally of a clear colour, or even sometimes completely white. We may therefore presume that the blackish turic of the compound eycs is destined, by absorbing a part of the rays of light, to diminish the sensibility of the optic nerves, while the almost colourless varnish of the smooth eyes, far from absorbing the luminous rays, serds them back, and thus increases the exciability of the retina formed by the sprending of the small optic nerves. It seems at least that it is in this respect that the smooth eyes may be useful to vision; for their smalness is so great, that without this arrangement they never could procure sensations very distinct.

Besides, the insects which have snooth eyes culy, have a greater number of them; and as their life is generally less active than that of the species which possess two kinds of eyes, we may presume that it was not necessary to them to pircive objects at distances so great. We observe also that jnsects which have smooth cyes only, keep almost constantly in dark places, or at least do not go great distances, being also deprived of the organs adapted for flying. The aplerce, and the numerous class of the larvæ of the lepidopterce, furnish a striking proof of this.

All the experiments which I made to determine to what extont the smooth eyes may be useful to the insects which present 
the two kinds of eyes, have scarcely given me any information as to the destination and utility of the former. I removed with the greatest care the smooth eyes from the respa gallica and vulgaris, as well as from the apis violacea and other hymenopterce, and from the apis philanthus and scolia. At the moment of their being remover, the privation seemed to retard their movements a little; but soon atterwards they acted as before. I never saw the wasps whose sn:ooth eyes 1 had removed or varnished over, at all embarrassed in taking fight again. The case was the same with the orthopterce which I submitted to similar tests : in short, all continued to move as before.

When, on the contrary, I passed a blackish varnish over the eompound eyes, or when I burst them, I saw the insects act completely as if they were blind, turning about in all directions, without being able to guide themselves. Thus they brushed against the wall, or any obstacle which I placed before them.

All the insects which I subjected to this lind of test seemed to draw their legs very frequently over their heads, as if to remove what hindered their eye-sight. In this state we also saw them make more frequent use of their antennæe, by directing them always forward and on one side, and feeling with the greatest celerity the objects which opposed their progress. This greater mobility of the antenne announced pretty well their uses: but in order to render them still more evident, I took some $l_{0 \text { - }}$ custa which have the antenne very long, and I touched these organs with oxy-muriatic acid. The insect was noways affected thereby; but as soon as this acid came near the eye-lids, and long before it could produce an immediate action on the eye itself, the insect darted away with rapidity, showing a great degree of anxiety. This experiment, which I repeated several times, and which always sticceeded, seems to confirm an opinion which I formerly hazarded on the use of the antenna and the palpebræ in certain classes of insects $*$.

In short, if we remove from the insects which have not compound eyes, their smoath eves, or if we cover them with an opaque varnish, we see them act as blindly as those which are deprived of their compound eyes. This experiment proves that, when insects have no other eyes than siruple eyes, the latter perform the offices of compound eyes. As to the smooth eyes united in the same individual to the compound eyes, they seem to be of very little use. Perhaps they are merely destined to strve for the vision of objects which strike directly the point where these eves are situated. Thus, the lateral eyes placed on the lateral summits of the head, would be destined to show the insect

* Vide my Memoir on the Sense of Smelling, and on the Orans which seem to be the Seat of it, in the Annules du Minstum d'Ilist. Nat. 
all external objects in this direction, while the smooth eye in the front and centre would inorm them of the obstacles which they might expect to find when artwucing in a straight lire. It is to be observed that, in this arangement, the Iateral smooth eyes are very little controted by the compeunt ejes, and that the eye in the centre is always calculated more directly for any obstacle which should oppose the advance ot the insect. Sometimes, however, the smooth eyes are arranged in the form of a triangle on the crown of the head; when they can only be useful in enabling the insect to pereeive objects placed above it. Indeed, those which exlibit this disposition lower the head so as to enable then to see straight forward. Bees and certain specics of wasps, as well as the manies, which have their smooth eyes on the summit of their head, know very wel! how to incline it, the better to distinguish objects placed before them.

The facts which we have detailed, seem positive enough to permit us to conclude,

1. That we must never judge of the extent or perfection of any sense, from the simplicity of the organ destined to produce it; for, if we regard only the little degree of complication in the eyes of insects, we might presume either that these animals do not see at all, or at least that they have not a very distinct vision. Facts, however, prove not only that they are not myopes, but also that they perceive objects at great distances.

2. That the eyes of insects have no relation with those of any other class, and that this organ, like all those of this order of animals, cannot be assimilated, nor even compared, to any other which performs the same functions in a different order of animals. Thus, we always run the risk of establishing inaccurate relations, when we endeavour to compare the organs of insects with those of the other invertebral animals, and $\dot{a}$ fortior $i$ with those of the vertebral. In fact, insects are so formed, on a particular plan, that we ought never to establish any parallel with respect to their organs, except between the species of different orders. We may therefore say that, correctly speaking, these animals ought to be compared with each other only, because, in the immense chain of organized beings, they alone present the remarkable peculiarity of having no other fluid in circulation but air. This disposition of not presenting any ramified vessels but those destined to give play, through all the parts of the body, to the impression of this subtle fluid, the aliment of life as it is of flame, ought necessarily to have brought with it a crowd of differences in organization, which we would seek for elsewhere in vain. The nervous system is the only one which still shows that all the articulated animals have been formed on 
one and the same plan; and although it undergoes fewer modifications than all the other systems, we see it exhibit peculiarities which eridently announce the absence of a centre of action in insects.

While this memoir was printing, I ascertained that the perfect insects which exist in water, exhilbit some peculiarities in their compound eye. Thus, as I have already remarked, this eye is always of a dark colour, which is owing jointly to the thickness of the tunic of the comea, to that of the varnish of the choroid, and finally, to that membrane itself. The varnish of the choroid, seen at its greatest thickness, appears to be of the deepest black; but when we stretch it, and reduce it to thin layers, it passes to the darkest violet. The thickness of the choroid is very remarkable in these species, particularly in the dytice and the hydrophyla. In both, the circular trachea is totally wanting: its place is ocmupied by a comnon trunk, from which issue two principal branches, which proceed to form aromid the optic nerve a network of trachex larger than the branches which furnish them. Finally, I have remarked that in most of the insects which live in water, the retina is very near the cornea, a disposition which is also observed in the snecies which are not properly lucifugce, but which habitually ty at sunset only, such as the geotrupe.

I have already observed that certain species presented several different shades in their compound eye; but, what is most singular, there are some in which this organ exhibits in its middle part a very narrow stripe of a colour totally different from the rest of the eye. 'This stripe, generally of a deep tint, is almost always placed in the middle of the eye, so that it separates it into two equal parts. But why is the tunic of the cornea thus of a different colour? It is difficult to account for this. This disposition, howerer, is not very rare; we see it even very decidedly in the locusta gigantea, the phasma rossia, as well as in certain species of syrphus and tabanus. The locusta litifolia* presents even several parallel stripes of a redlish brown, whereas the rest of the eye is of a whitish green: what is most particular is, that its stripes do not exist in the middle of the eye. I have deseribed in the course of this memoir the compound eyes of the cloportae, thinking that they were true insects, i.e. articulated animals deprived of a circulation of blood, but furnished with trachex. Subsequently 1 have made new researches as to the organs of circulation of a great number of

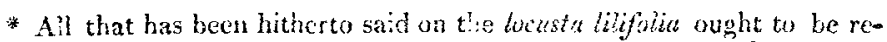
furred to the locista facata. These two nawes iave been confounded by mistalie. 
invertebral animals, and these inquiries have proved that the cloporta, which I had placed among the insects, belonged to the class of arachnoides; and that phalangia, which I had presumed to have the same organization with the spiders, ought to be classed with the insects, since they present trach ax and a dorsal vessei withrut vasenlar ramifications. As to the cloporice, they bave a true heart provided with ressels, the blood of which goes to receive the irnpression of the air, into particular organs not ranified, and which we may consider as species of lungs. With respect to the organs of circulation and respiration, the cloporice are nearer the scorpions than the spiders. In fact, the latter have a heart very much enlarged at its base: although this heart extends afterwards to the extremity of the body, it by this enlargement resembles that of the crustaceous decapodes, with this difference, however, that the position of these two organs is not the same. The heart of the crustacere is situated in the breast, while that of spiders is in the abdomen and the side of the back. As to the heart of scorpions, we do not see that it has any very sensible enlargements; in this respect this organ more resembles the heart of the cloportce than that of the spiders. But it is truly worthy of remark, that the organs of respiration are multiplied in proportion as the heart takes an uniform diameter. Thus in the spider, in which the heart is decidedly swollen, there exist only two lungs : in the cloportce the heart, without showing any sensible enlargement, as in the spider, nevertheless presents a diameter a little more considerable towards its upper part: thus we observe they have four lungs: finally, in the scorpions this number amounts to eight; but the heart in all these animals is of a diameter nearly uniform throughout its whole extent. To conclude: in all the arachnoides the lungs are always symmetrical, and are never found but in pairs. It is possible that the form of body may also have -some influence on that of the organs of respiration, and particularly of circulation. 'Thus the greatest diameter of the heart in certain species of spiders would supply what was wanting in length. Nevertheless, this cause ought not alone to have infuence, since in all the spider race the heart extends from one extremity of the body to another. The heart of the spiders begins, in fact, at the bottom of the abdomen; but as it sends two principal vessels into the breast, we may say that it extends from one extremity of the body to the other.

As to the nervous system of the true spiders, it is always composed of a cerebriform ganglion, situated in the upper part of the body, which we may either call head or breast, because it performs functions analogous to those two parts. This ganglion, situated above the oesophagus, surrounds it most frequently Vel.44. No.198. Oct.1814. 
by prolonging itself afterwards into two cordons, which form new ganglions, from which other newes issue wholly as if from the brain. But in the insects, we lsnow that there exist as many ganglions as there are rings, rhile in the true arachnoides this number is always far less considemble. Besides, in the articulated animals, the nerrous system in general undergoes few variations; it even shows in an evident namner, that ail these animals have been formed on one and the same plan, which has merely undergone some trifing modifications adapted to peculiar circumstances.

From what we have observed, there will be some change necessary in the classification of the articulated animals, and the class of insects will be better distinguished from that of the arachnoides than it has been hitherto; for these animals differ from each other in their organs of respiration and circulation, and even, although in a manner less striking, in those of reproduction and nutrition. This branch of the subject will form a separate memoir, on the organs of circulation and respiration of some families of articulated animals. In the mean time we shall observe, that the arachnoides are divided naturally enough into two principal families, the oviparous arachnoides and the viviparous arachnoides. It is besides very singular, to find this mode of gestation in animals whose organization is also very simple; for their system of respiration may be assimilated, under certain points of view, to that of some crustaceous decapodes with long tails: as to their circulation, it is purely pulmonary. The division of the arachnoides which we have mentioned, is, as we see, very different from that hitherto adopted; indeed this division will fall of itself to be still more subdivided, in order to place each genus in the most natural order. In this classification the arachnuides will always come after the crustacece; but the order in which the insects have been usually arranged must be totally inverted. Thus, instead of terminating the series of insects by the apterce, as several naturalists have done, we must on the contrary commence with them, since most of the apterce have a greater affinity with certain arachnoides.

The common spiders having ramified respiratory organs or trachex, and being thereby deprived of an organ of circulation furnished with vessels, are true insects; I ought, therefore, to say a few words with respect to their eyes.

The eyes of the phalangium are situated nearly like those of the crustacece, with which the common spider has besides some relations, either from the disposition of their bodies, and of their organs of movement, or, finally, by the volume of their hepatic vessels, or their livers. Thus, the position of the smooth eyes of the common spider (noothers are observedin this genus) is considerably different 
from that of the eyes of the other apterce. The cornea is all of a piece, as in the smooth eves : it seems externally of a brilliant black; but this colour does not belong to its texture; it is produced by the tunic of that membrane which presents this shade. This comea is very convex, rounded, and polished. Placed in a projection of the head, the eyes of the spider are very close to each other, being only separaied by a deep sinus. The eyes are placed a little on one side of the projection which forms the coriaceous envelope, so that they ought not to be able to distinguish objects except above them and laterally. As they are immoveable as well as the parts on which they are situated, it must be difficult for the plalangium to perceive objects placed in a straight line with the bouly. This position of the eyes is the more remarkable, as it is the only one of this kind which exists in insects. It is not found in the arachnoides, and is only seen in certain species of crustacece, and still under many nodifications.

The eyes of the phalangium are protected by an interorbitary arcade, and this forms above them a projection for defending them a rainst the impression of external objects. These eyes, so far as their diminutive size has permitted me to judge, are formed by a cornea of one hard piece, thick, convex, and transparent. It seems, however, to be black when viewed externally; but this is orving, as we have already said, to the colouring of the tunic placed under this membrane. This tunic is besides very thick. We see it traverged by a nerve which corresponds with the concave surface of the cornea. The choroid and its varnish are completely black: probably, the texture of this membrane is formed by trachex, nevertheless it is not surrounded by a circular trachea. There proceed towards this part numerous tracheæ, but they are there ramified, instead of forming a principal trachea. This is nearly all that I could ascertain respecting the structure of the eyes of this kind of spider, so similar to the arachnoides in external character, and yet so different in the organs of respiration and circulation.

Having been able quite recently to ascertain the structure of the compound eyes of the crepuscular insects, such as the sphynx and the noctuce, I ought to state that nothing which I have said on the vision of insects in general is applicable to them. The latter have, in fact, an organization so particular in the structure of their eyes, that there is necessarily a great difference in the way in which vision is effected. I thought I recognised in these eyes humours of different densities, and even a species of crystalline; we know that there exists nothing similar in the other insects.

These are the differences which exist between order and order, $\mathrm{T} 2$ 


\section{On a Subsitute for Coffee proposed by a French Author.}

and which render the anatomy of insects so intricate, particularly when we wish to deduce general conclusions from observations made upon a great number of individuals. We may also add to these difficulties, which are immense, and which we can never be certain of having surmounted, those which result from the uncertainty in which we still are, respecting the organization of the great class of articulated animals. Indeed, these difficulties are the greater, because the classes of articulated animals are much less striking, and less clearly separated, than those of the other ramifications. Thus we cainot have recourse to analogy to judge a priori of the organization of these animals. The anatonist who should take into the labours of classificators the basis of his own researches, would run the risk of falling into greater errors, if he examined but one organ only, and he would surely bring together aninals separated by their whole organization.

To conclude: we may have fallen into errors in the course of our investigation ; but, as truth was the object of all our efforts, we trust we shall be forgiven.

XLV. On a Substicute for Coffee, proposed by a French Author.

\section{To $M r$. Tillach.}

Sir, - Trusting that you will always have the candour, in your valuable publication, to award the priority of any discovery to those who may have a just right to claim it, I take the liberty, through that channel, of suggesting, that the discovery of the seeds of the Iris pseudacorus, or common vellow water flag, as an excellent substitute for coffee, was not made by M. Levrat, as stated in the Philosophical Magazine for August, page 144, but by myself in the year 1809 , as may be seen in the twentysecond volume of Nicholson's Philosophical and Chemical Journal, where my account of it is published. And as that paper was soon noticed by Morveau, in the Annales de Chimie, the subject might have been suggested to $M$. Levrat by either of these sources; and I am happy to find that my opinion of the usefulness of these seeds is likely to be acted upon for the benefit of our species.

Wislech, Sept. 6, 1814.

I remain, yours, \&c.

WM. SxRIMSHIRF, Jun.

XI.VI. Bio- 